\title{
Control of Fusarium Wilt of Radish by Combining Pseudomonas putida Strains that have Different Disease-Suppressive Mechanisms
}

\author{
Marjan de Boer, Peter Bom, Frodo Kindt, Joost J. B. Keurentjes, Ientse van der Sluis, \\ L. C. van Loon, and Peter A. H. M. Bakker
}

Institute of Biology, Section of Phytopathology, Utrecht University, Utrecht, the Netherlands. Accepted for publication 9 January 2003.

\begin{abstract}
de Boer, M., Bom, P., Kindt, F., Keurentjes, J. J. B., van der Sluis, I., van Loon, L. C., and Bakker, P. A. H. M. 2003. Control of Fusarium wilt of radish by combining Pseudomonas putida strains that have different disease-suppressive mechanisms. Phytopathology 93:626-632.

Biological control of soilborne plant pathogens in the field has given variable results. By combining specific strains of microorganisms, multiple traits antagonizing the pathogen can be combined and this may result in a higher level of protection. Pseudomonas putida WCS358 suppresses Fusarium wilt of radish by effectively competing for iron through the production of its pseudobactin siderophore. However, in some bioassays pseudobactin-negative mutants of WCS358 also suppressed disease to the

same extent as WCS358, suggesting that an, as yet unknown, additional mechanism may be operative in this strain. P. putida strain RE8 induced systemic resistance against fusarium wilt. When WCS358 and RE8 were mixed through soil together, disease suppression was significantly enhanced to approximately 50\% as compared to the $30 \%$ reduction for the single strain treatments. Moreover, when one strain failed to suppress disease in the single application, the combination still resulted in disease control. The enhanced disease suppression by the combination of $P$. putida strains WCS358 and RE8 is most likely the result of the combination of their different disease-suppressive mechanisms. These results demonstrate that combining biocontrol strains can lead to more effective, or at least, more reliable biocontrol of fusarium wilt of radish.
\end{abstract}

Studies on biological control of Fusarium wilts caused by formae speciales of Fusarium oxysporum have a long history because available control methods are either inefficient or difficult to apply (1). Also, the concern for environmental protection renewed interest in biological control of soilborne diseases (59). Fusarium wilts particularly can be suppressed through the activity of fluorescent Pseudomonas spp. strains and nonpathogenic strains of $F$. oxysporum. The disease-suppressive mechanisms of these biocontrol agents include siderophore-mediated competition for iron $(3,46,49)$, competition for substrate $(6)$, induction of systemic resistance $(12,29,44,55,56,58)$, and production of antibiotics $(2,5)$. Production of chitinolytic enzymes is hypothesized to be responsible for suppression of fusarium wilt of cucumber by Paenibacillus sp. and Streptomyces sp. strains (53). Unfortunately, due to the complexity of the biotic and abiotic interactions that play a role in biological control, the practical results with biocontrol of soilborne pathogens have been variable (17). Failure of the introduction of antagonistic microorganisms seems to be due to environmental factors resulting in inadequate distribution, insufficient establishment of rhizobacterial strains, or poor expression of their antagonistic activity (50).

One possible approach to improve biological control may be the application of combinations of biocontrol agents (8). By combining microorganisms, multiple antifungal traits can be combined and one may assume that at least one biocontrol mechanism will be functional under the conditions faced by the released biocontrol agents. Moreover, combinations of biocontrol strains are expected to result in a higher level of protection (10), have reduced vari-

Corresponding author: P. A. H. M. Bakker

E-mail address: P.A.H.M.Bakker@bio.uu.nl

Publication no. P-2003-0317-01R

(C) 2003 The American Phytopathological Society ability of biological control $(15,16)$, and have potential to suppress multiple plant diseases (21). It has been demonstrated that natural suppressiveness of the Châteaurenard soil in France against Fusarium wilt is based on various mechanisms involving several microbial populations acting alone or together to limit the activity of the pathogen (1). In fact, several authors have demonstrated that combining microorganisms can result in improved plant stand $(4,19)$. Mixtures of biocontrol agents also resulted in enhanced control of several fungal and bacterial plant diseases $(20,26,38,43$, $48,51,53)$. Dunne et al. (10) demonstrated that combining phloroglucinol-producing and proteolytic bacteria improved biocontrol of Pythium-mediated damping-off of sugar beet. By combining the nonpathogenic $F$. oxysporum strain Fo47 with the bacterial strain Pseudomonas putida WCS358, two different disease-suppressive mechanisms acted together to enhance suppression of Fusarium wilt of carnation and flax $(9,31,32)$. In these situations, the pseudobactin siderophore of WCS358 increased the intensity of the antagonism of Fo47 against the pathogenic F. oxysporum by making the pathogen more sensitive to competition for carbohydrates by Fo47 (32). Sung and Chung (54) showed that a mixture of bacteria that produce chitinases and antibiotics can effectively suppress rice sheath blight caused by Rhizoctonia solani.

Such enhanced disease suppression may involve not only different disease-suppressive mechanisms, but can also result from interactions between the introduced strains that positively influence growth, root colonization and/or activity of the strains. On the other hand, interactions between two or more introduced biocontrol strains can also negatively influence disease control. For instance, siderophore-mediated competition for iron or competition for substrate may limit the colonization or activity of introduced biocontrol strains $(24,47)$. De Boer et al. (7) demonstrated that $P$. putida strain RE8 inhibits growth of $P$. fluorescens strain RS111 in vitro. The combination of these two strains did not improve control of Fusarium wilt of radish, whereas the combination 
of RE8 with RS111-a, a spontaneous mutant of RS111 that was no longer inhibited in growth by RE8, did result in enhanced disease suppression.

The combination of $P$. putida strains WCS358 and RE8 was previously demonstrated to enhance suppression of Fusarium wilt of radish (7). This enhanced suppression is likely to be based on different mechanisms. The disease-suppressive mechanism of strain RE8 is as yet unknown, whereas for strain WCS358, it was demonstrated that pseudobactin production is involved $(26,46)$. In the present study, the involvement of siderophores and induced systemic resistance in disease suppression by RE8 and WCS358 was investigated. Furthermore, the population dynamics of both strains in the rhizosphere were investigated in both the single strain and combination treatments to assess effects on root colonization.

\section{MATERIALS AND METHODS}

Microbial cultures. $P$. putida strains WCS358, RE8, and other strains and derivatives used are listed in Table 1. A pseudobactinnegative mutant of RE8 (RE8-30) was obtained by Tn5 transposon mutagenesis according to Marugg et al. (39) using Escherichia coli S17-1 harboring plasmid pSUP2021. A derivative of WCS358, WCS358pvd-inaZ, was used to determine iron availability in the rhizosphere (9). The $p v d$-inaZ construct consists of an 8 -kb EcoR1 fragment containing pyoverdine $(p v d)$ production and uptake genes from $P$. syringae cloned $5^{\prime}$ to a promoterless ice nucleation gene (inaZ) in plasmid pVSP61 (36). The ironregulated $p v d$ promoter fused to $i n a Z$ in the $p v d$-inaZ construct initiates transcription of a gene encoding a ferric-pyoverdine receptor protein. Pvd-inaZ was introduced in WCS358 by conjugation with an E. coli donor strain, as described previously (34). The pathogen used was $F$. oxysporum Schlecht f. sp. raphani Kendrick and Snyder strain WCS600 (30). All strains were stored at $-80^{\circ} \mathrm{C}$ in $50 \%$ glycerol.

Isolation of a pseudobactin nonproducing mutant of RE8. To perform random mutagenesis of $P$. putida strain RE8, the mobilization system of $E$. coli strain S17-1 and the suicide vector pSUP2021 carrying transposon Tn5 were used. Cells of donor $E$. coli S17-1 harboring pSUP2021 and recipient $P$. putida strain RE8 were grown in liquid Luria-Bertani (LB) medium (42) at $37^{\circ} \mathrm{C}$ and liquid King's medium B $\left(\mathrm{KB} ; 23\right.$, ) at $28^{\circ} \mathrm{C}$, respectively. After overnight growth to late log-phase, suspensions of both strains were mixed in an Eppendorf tube (ratio 1:1) and concentrated by centrifugation (30 s). The mating mixture was carefully resuspended in $50 \mu \mathrm{l}$ of LB medium and spread on a Millipore filter (0.45 $\mu \mathrm{m}$; Millipore, Etten Leur, the Netherlands) on LB-agar plates. After incubation for $24 \mathrm{~h}$ at $28^{\circ} \mathrm{C}$, cells on the filter were suspended in $1 \mathrm{ml}$ of $\mathrm{KB}$ medium, and $100 \mu \mathrm{l}$ portions were spread on KB-agar plates supplemented with $50 \mu \mathrm{g}$ of kanamycin $(\mathrm{Km})$ per ml (Sigma, St. Louis, MO) and $25 \mu \mathrm{g}$ of nalidixic acid (Nx) per ml (Sigma) to select for Pseudomonas cells that had acquired the transposon and to select against $E$. coli, respectively. Recombinant colonies appeared on the plates after incubation for $48 \mathrm{~h}$ at $30^{\circ} \mathrm{C}$. Single colonies were then screened for nonfluorescence on KB-agar plates and for nonhalo formation on chrome azurol S medium (CAS) plates (52). When the bacterial colonies sequester iron from the green CAS plates, an orange halo appears around the colonies. Several transconjugant colonies that were nonfluorescent and did not produce a halo on CAS plates were checked for single transposition events by hybridization. Total DNA from $\mathrm{Km}^{\mathrm{r}}$ mutants was isolated, digested with EcoRV, which has no recognition sites in $\operatorname{Tn} 5$ (22), or SalI, which has one recognition site in $\operatorname{Tn} 5$ (22), and blotted on a positively charged nylon membrane (Boehringer Mannheim, Almere, the Netherlands). The membrane was hybridized with digoxigenin (DIG)labeled probe against the internal HindIII fragment of Tn5 using high stringency conditions. Hybridization was assessed using the
DIG-luminescent detection kit (Boehringer Mannheim Biochemica, Almere, the Netherlands).

In vitro interactions between Pseudomonas strains. Bacterial suspensions were made by suspending cells cultured for $24 \mathrm{~h}$ at $28^{\circ} \mathrm{C}$ on $\mathrm{KB}$-agar plates in sterile $10 \mathrm{mM} \mathrm{MgSO}_{4}$. Densities of the bacterial suspensions were determined spectrophotometrically at $660 \mathrm{~nm}$. The bacterial strains were adjusted to $10^{7} \mathrm{CFU} / \mathrm{ml}$ and two droplets of $5 \mu \mathrm{l}$ were spotted on $\mathrm{KB}$-agar plates, each approximately $1.5 \mathrm{~cm}$ from the edge. To determine the influence of iron-regulated metabolites, such as pseudobactins, the same experiment was performed on KB agar supplemented with $200 \mu \mathrm{M}$ $\mathrm{FeCl}_{3}$. The spot-inoculated plates were incubated at $28^{\circ} \mathrm{C}$ for $48 \mathrm{~h}$. Subsequently, a suspension of the target strain $\left(10^{7} \mathrm{CFU} / \mathrm{ml}\right)$ was atomized over the spot-inoculated plates, and zones of growth inhibition of the target strain around the spot-inoculated strains were measured after an additional incubation period of $24 \mathrm{~h}$ at $28^{\circ} \mathrm{C}$.

Preparation of inoculum of the antagonists. Bacteria were grown for $24 \mathrm{~h}$ at $28^{\circ} \mathrm{C}$ on $\mathrm{KB}$-agar plates, and suspensions were prepared in sterile $10 \mathrm{mM} \mathrm{MgSO}_{4}$. The bacterial strains were introduced in an autoclaved $(2 \times 20$ min with a $24 \mathrm{~h}$ interval $)$ potting soil-sand mixture (46) to a density of approximately $7 \times$ $10^{6} \mathrm{CFU} / \mathrm{g}$ of potting soil-sand mixture. When combinations of strains were used, each strain was introduced at a density of $7 \times$ $10^{6} \mathrm{CFU} / \mathrm{g}$. Inoculum for the induced systemic resistance experiments were prepared by mixing the bacterial suspensions with talcum (1:1, vol/wt) to a final density of $5 \times 10^{7} \mathrm{CFU} / \mathrm{g}(29)$.

Preparation of inoculum of $F$. oxysporum f. sp. raphani. $F$. oxysporum f. sp. raphani was cultured in aerated $2 \%$ malt extract (Difco, Detroit, MI) medium at $22^{\circ} \mathrm{C}$. After 14 days of growth, cultures were filtered through sterile glass wool to remove mycelial mats. Microconidia were harvested by centrifugation at $8,000 \times g$ for $20 \mathrm{~min}$, resuspended in $10 \mathrm{mM} \mathrm{MgSO}_{4}$, and mixed through a potting soil-sand mixture $(12: 5, \mathrm{vol} / \mathrm{vol})$ to a density of $3.75 \times 10^{5} \mathrm{CFU} / \mathrm{g}$. Infested soil was incubated in polyethylene bags for 3 to 5 days at $20^{\circ} \mathrm{C}$ before use in the potting soil bioassays to allow colonization of the soil by the pathogen. The inoculum for the induced systemic resistance experiments was prepared as described above, except $F$. oxysporum f. sp. raphani was mixed through a peat-sand $(1: 1, \mathrm{vol} / \mathrm{vol})$ mixture to a density of $3 \times 10^{4} \mathrm{CFU} / \mathrm{g}$.

Suppression of Fusarium wilt in potting soil. Effects of single strains and their combinations on Fusarium wilt in radish were tested in a potting soil bioassay (7). For this bioassay, the $F$. oxysporum f. sp. raphani-infested soil, bacterized soil, additional autoclaved soil, and nonautoclaved river sand were mixed in order to obtain final densities of $10^{4}$ conidia per $\mathrm{g}$ of soil of $F$. oxysporum f. sp. raphani and $10^{6} \mathrm{CFU} / \mathrm{g}$ of soil of each bacterial strain. Per treatment, 9 pots $(11 \mathrm{~cm}$ high and $14 \mathrm{~cm}$ in diameter) were filled with $750 \mathrm{~g}$ of the soil-sand mixture, in which 10 radish seeds (Raphanus sativus L., cv. Saxa $2 *$ Nova; S\&G Seeds B.V.,

TABLE 1. Pseudomonas spp. strains used in this study

\begin{tabular}{|c|c|c|}
\hline Microbial culture & Characteristics & Reference \\
\hline E. coli $\mathrm{S} 17-1$ pSUP2021 & $\mathrm{Cm}^{\mathrm{r}} \mathrm{Nm} / \mathrm{Km}^{\mathrm{r}} \mathrm{Ap}^{\mathrm{r}} \mathrm{Mob}^{+} \mathrm{Tc}:: \mathrm{Tn} 5$ & 22 \\
\hline P. fluorescens WCS417 & Isolated from wheat rhizosphere & 25 \\
\hline P. putida RE8 & Isolated from radish roots, $\mathrm{Nx}^{\mathrm{r}}$ & 7 \\
\hline RE8-30 & $\begin{array}{l}\text { Pseudobactin-negative Tn5 } \\
\text { transposon mutant of RE8, } \mathrm{Km}^{\mathrm{r}}\end{array}$ & This study \\
\hline P. putida WCS358 & Isolated from potato rhizosphere & 13 \\
\hline WCS358r & $\begin{array}{l}\text { Rifampicine-resistant derivative of } \\
\text { WCS358 }\end{array}$ & 14 \\
\hline JM213 & $\begin{array}{l}\text { Pseudobactin-negative } \mathrm{Tn} 5 \text { trans- } \\
\text { poson mutant of WCS } 358, \mathrm{Km}^{\mathrm{r}}\end{array}$ & 39 \\
\hline JM214 & $\begin{array}{l}\text { Pseudobactin-negative Tn5 trans- } \\
\text { poson mutant of WCS } 358, \mathrm{Km}^{\mathrm{r}}\end{array}$ & 39 \\
\hline JM218 & $\begin{array}{l}\text { Pseudobactin-negative Tn5 trans- } \\
\text { poson mutant of WCS358, } \mathrm{Km}^{\mathrm{r}}\end{array}$ & 39 \\
\hline WCS358pvd-inaZ & $\begin{array}{l}\text { Reporter strain WCS358, contain- } \\
\text { ing a pvd-inaZ fusion, } \mathrm{Km}^{\mathrm{r}}\end{array}$ & 9 \\
\hline
\end{tabular}


Enkhuizen, the Netherlands) were sown. The plants were grown in a climatized greenhouse at $20^{\circ} \mathrm{C}$ and $70 \%$ relative humidity with a photoperiod of $16 \mathrm{~h}$. Plants were watered with tap water once a week, and once a week received half-strength Hoagland solution (18). In those bioassays where addition of iron was required, the solution was supplemented with $10 \mu \mathrm{M}$ Fe-EDDHA (ethylenediaminodi( $o$-hydroxyphenyl) acetic acid). After approximately 21 days the percentage of diseased plants per pot was scored on the basis of both external wilting and internal browning symptoms (26). The experiment was conducted at least two times for all bacterial treatments.

Suppression of Fusarium wilt by induced systemic resistance. This bioassay was conducted as described by Leeman et al. (29). Radish seeds (cultivar Saxa $2 *$ Nova) were sown in sand and after 5 days, seedlings were transferred to rock wool cubes (Rockwool/Grodan b.v. Roermond, the Netherlands), in such a way that the root system was divided over two cubes. The biocontrol bacteria were inoculated on the lower part of the root system at the root tips, and $F$. oxysporum f. sp. raphani was delivered in the peat and sand mixture at the part of the root system near the stem 2 days later. The populations of the biocontrol bacteria and $F$. oxysporum f. sp. raphani remained spatially separated throughout the experiment avoiding direct interactions between the biocontrol strains and the pathogen. The plants were grown in a climatized greenhouse as describe above. Plants were watered with deionized water and once a week received half-strength Hoagland solution with iron (Fe-EDDHA, $100 \mu \mathrm{M})$ (18). Twenty-eight days after transplanting, plants were scored for both external wilting and internal browning symptoms (26). The experiment was conducted two times.

Root colonization by introduced bacterial strains. In bioassays in which suppression of Fusarium wilt in potting soil was studied, colonization by strains WCS358 and RE8 was determined at two time points. When sampling plants for root colonization, the soil surrounding the root system was loosened and two root systems, randomly chosen from the 10 plants per pot, were harvested. For each treatment, six replicates were used. The samples were suspended in $10 \mathrm{ml}$ of sterile $10 \mathrm{mM} \mathrm{MgSO}_{4}$ and shaken vigorously for $30 \mathrm{~s}$ (Vortex shaker at maximum speed) in glass tubes containing $0.5 \mathrm{~g}$ of glass beads $(0.56$ to $0.80 \mathrm{~mm}$ in diameter). Aliquots $(100 \mu \mathrm{l})$ of serial dilutions of these rhizosphere samples were mixed homogeneously with $300 \mu$ selective $\mathrm{KB}^{+}$ agar at $45^{\circ} \mathrm{C}$ (KB supplemented with $100 \mu \mathrm{g}$ of cycloheximide per $\mathrm{ml}, 40 \mu \mathrm{g}$ of ampicillin per $\mathrm{ml}$, and $13 \mu \mathrm{g}$ of chloramphenicol per $\mathrm{ml}$ ) [13], and amended with $150 \mu \mathrm{g}$ of rifampin per ml [Sigma] for WCS358r) in 24-well tissue culture plates on a reciprocal shaker to mix the sample through the not yet solidified agar. After incubation for $24 \mathrm{~h}$ at $28^{\circ} \mathrm{C}$, the number of bacterial colonies that had developed inside the agar was determined. Numbers of strain WCS358r were determined by counting the colonies in $\mathrm{KB}^{+}$agar amended with rifampin under the microscope. Colonies of strain RE8 were enumerated by immunofluorescence colony staining (IFC) according to the method described by Van Vuurde (57), as modified by Leeman et al. (28). For IFC, wells were incubated with a 40-fold dilution of a fluorescein isothiocyanate-conjugated

TABLE 2. Population densities on radish roots of $P$. putida strains WCS358r and RE8 when applied alone or in combination at 13 and 25 days after sowing

\begin{tabular}{lccccc}
\hline & \multicolumn{3}{c}{ Population density } & $\left({ }^{10} \log \text { CFU/g of root }\right)^{\mathrm{z}}$ \\
\cline { 2 - 3 } \cline { 5 - 6 } Strains & \multicolumn{2}{c}{13 days } & & \multicolumn{2}{c}{25 days } \\
\cline { 2 - 3 } \cline { 5 - 6 } WCS358r & Single & Combination & & Single & Combination \\
RE8 & $6.22 \mathrm{~b}$ & $5.91 \mathrm{a}$ & & $6.08 \mathrm{~b}$ & $5.59 \mathrm{a}$ \\
\hline
\end{tabular}

${ }^{\mathrm{z}}$ Means at each time point followed by different letters are significantly different according to the protected least significant difference test at $P=$ 0.05 using the analysis of variance model in SPSS. polyclonal rabbit antiserum raised against and specific for strain RE8. Colonies were counted using a Zeiss Axioskop 20 (Carl Zeiss, Inc., Oberkochen, Germany) fluorescence microscope. The experiment was conducted three times.

Effects of iron availability on pseudobactin production and ice nucleating activity (INA) of WCS358pvd-inaZ in culture. Erlenmeyer flasks $(100 \mathrm{ml})$ with $30 \mathrm{ml}$ of liquid standard succinate medium (SSM) (41), containing different concentrations of Fe-EDDHA, were inoculated in duplicate for each iron concentration with $0.3 \mathrm{ml}$ of a washed suspension of $P$. putida strain WCS358 or reporter strain WCS358pvd-inaZ from an overnight SSM culture supplemented with $100 \mu \mathrm{M}$ Fe-EDDHA. After $48 \mathrm{~h}$ of growth at $28^{\circ} \mathrm{C}$ on a reciprocal shaker at $250 \mathrm{rpm}$, the numbers of CFU, pseudobactin production by WCS358, and the INA of WCS358pvd-inaZ were determined. The numbers of cells in the cultures were determined by plating appropriate dilutions on KBagar plates using a spiral plater (Spiral Systems, model cu, Cincinnati, $\mathrm{OH}$ ) and counting colonies after $24 \mathrm{~h}$ of incubation at $28^{\circ} \mathrm{C}$. Pseudobactin358 production in culture supernatants $(\mathrm{pH}$ 7.1) was determined spectrophotometrically using a molar extinction coefficient of 14000/M.cm $(\mathrm{pH}=7.1)$ at $400 \mathrm{~nm}(45)$. INA was quantified by the droplet freezing assay described by Lindow (33). The number of frozen droplets was scored after $4 \mathrm{~min}$ at $-10^{\circ} \mathrm{C}$. INA was expressed as ${ }^{10} \log$ (ice nuclei per $\mathrm{CFU}$ ). The experiment was conducted three times.

Assessment of INA in the rhizosphere. To determine iron availability in the rhizosphere, WCS358pvd-inaZ was introduced onto radish roots. Bacteria were mixed with the potting soil and sand mixture to a concentration of $10^{6} \mathrm{CFU} / \mathrm{g}$. Radish seedlings were grown for 5 days in river sand before transplanting five seedlings per pot in bacterized soil. For each treatment, 5 replicate pots were used. The seedling roots were sampled at different time intervals after planting. The root systems from each pot were transferred to a glass tube containing $10 \mathrm{ml}$ of $10 \mathrm{mM} \mathrm{MgSO}_{4}$ and glass beads. The tubes were shaken on a vortex for $30 \mathrm{~s}$. After appropriate dilution of the suspension, the INA was determined and related to the number of CFU, determined in 24-microwell plates with $\mathrm{KB}^{+}$amended with $50 \mu \mathrm{g}$ of kanamycin per $\mathrm{ml}$. The experiment was conducted two times.

Data analysis Rhizosphere populations of introduced bacterial strains approximate a log normal distribution along the root system (37). Therefore, the numbers of CFU were transformed to ${ }^{10} \log (\mathrm{CFU}+1)$ prior to statistical analysis (analysis of variance [ANOVA] followed by Fisher's least significant difference [LSD] test).

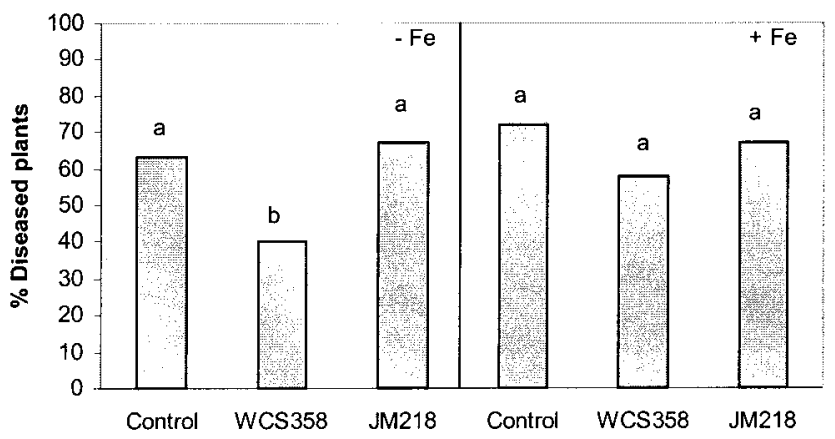

Fig. 1. Suppression of Fusarium wilt of radish in potting soil by $P$. putida strain WCS358 or its pseudobactin-negative mutant JM218. Strains were mixed through soil to a final density of $10^{6} \mathrm{CFU} / \mathrm{g}$ of soil. The pathogen was mixed through soil to a final density of $10^{4}$ conidia per $\mathrm{g}$ of soil. After mixing bacterized soil, Fusarium-inoculated soil and sand, radish seeds were sown. In the treatment with $\mathrm{Fe}(+\mathrm{Fe})$, plants received nutrient solution amended with Fe-EDDHA $(10 \mu \mathrm{M})$. Disease was scored 21 days after sowing. Bars with the same letter are not significantly different at $P \leq 0.05$; according to analysis of variance followed by Fisher's least significant difference test. Control treatment is Fusarium alone. 
Percentages of diseased plants of two bioassays were pooled after establishing that there was no significant interaction at $P=$ 0.05 between experiments and treatments and variances were homogeneous. The pooled data were tested for significance using ANOVA followed by Fisher's LSD test $(P=0.05)$, using SPSSsoftware (version 10.0 for windows; SPSS Inc., Chicago, IL).

\section{RESULTS}

Selection of a pseudobactin negative mutant of RE8. Of 300 transconjugants of RE8, 18 colonies produced no halo or a smaller halo on CAS medium as compared to the wild-type strain. One of these that did not fluoresce on $\mathrm{KB}$ and did not produce a halo on CAS medium was used for further study and labeled strain RE830. Northern blot analysis revealed that RE8-30 contained a single transposon insertion.

In vitro and in vivo interactions between $P$. putida strains. Interactions between $P$. putida strains WCS358 and RE8 and the pseudobactin-negative mutants of WCS358 (JM218) and RE8 (RE8-30) were studied on $\mathrm{KB}$ agar without and with $\mathrm{FeCl}_{3}$ $(200 \mu \mathrm{M})$. Strain WCS358 inhibited growth of strains RE8 and RE8-30 only on unamended plates. Neither RE8 nor the pseudobactin-negative mutant JM218 inhibited the growth of other strains tested regardless of the iron availability in the medium.

To investigate whether an inhibitory effect of WCS358 on growth of RE8 occurred in the rhizosphere, population densities on radish roots were determined upon application of either the single strains or their combination (Table 2). Surprisingly, the population density of RE8 when combined with WCS358r was significantly higher at 13 days after sowing as compared to the single inoculation. After 25 days, there was no difference for RE8 populations between the single and combination treatments. In two independent bioassays, the population density of WCS358r when combined with RE8 decreased significantly compared to the single strain application. Whereas the population density upon single application was maintained at over $10^{6} \mathrm{CFU} / \mathrm{g}$ of root, it was decreased in the combination treatment by a factor 2 or 3 at 13 and 25 days, respectively (Table 2).

Disease suppression by WCS358. When no iron was added to the Hoagland nutrient solution for the plants, WCS358 was able to suppress the percentage of diseased plants significantly (Fig. 1). Under these conditions, the pseudobactin-negative mutant JM218 did not suppress disease. When iron was added to the Hoagland solution, WCS358 and JM218 no longer suppressed disease significantly (Fig.1).

In some bioassays, pseudobactin mutants of WCS358 suppressed disease as well as the wild-type strain. In six of 12 bioassays, WCS358 suppressed disease significantly, whereas the pseudobactin mutant did not. In two bioassays, no disease suppression occurred by the wild type or the mutant. Surprisingly, in four bioassays, both WCS358 and the mutants were able to

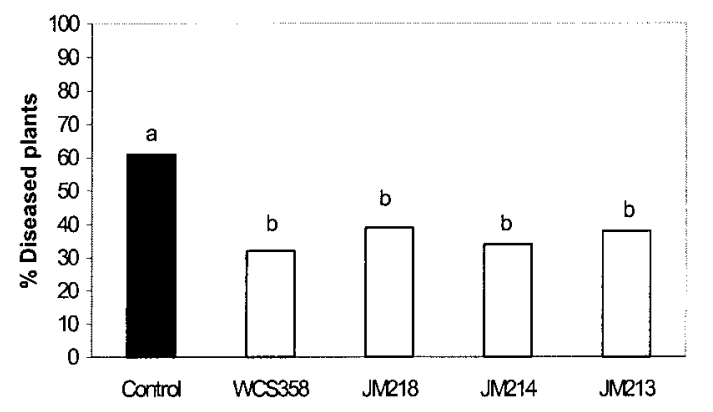

Fig. 2. Suppression of Fusarium wilt of radish in potting soil by $P$. putida strain WCS358 or its pseudobactin-negative mutants JM218, JM214, or JM213. Details as described in the legend to Figure 1. Control treatment is Fusarium alone. significantly suppress disease to the same extent. In two of these bioassays, different pseudobactin-negative mutants of WCS358 (JM218, JM213, JM214) were tested and all suppressed disease to the same extent as wild-type WCS358 (Fig. 2). Thus, under certain so far unidentified circumstances, pseudobactin-negative mutants of WCS358 can also suppress Fusarium wilt.

It was considered that in the two bioassays in which WCS358 did not significantly suppress disease, the potting soil used might have been relatively high in bio-available iron content, repressing the production of pseudobactin by WCS358. To estimate iron availability for WCS358 in the rhizosphere of radish plants grown in this soil, the reporter strain WCS358pvd-inaZ (35) was used. A standard curve of INA as a function of available Fe was determined by growing the reporter strain in liquid medium supplemented with different concentrations of Fe-EDDHA. After $48 \mathrm{~h}$, the presence of Fe-EDDHA did not have a clear effect on bacterial growth, but pseudobactin production decreased with increasing Fe-EDDHA concentration and no production occurred at concentrations of $10.0 \mu \mathrm{M}$ and higher. In general, INA decreased with increasing Fe-EDDHA concentration. However, the INA in flasks supplemented with 0.1 to $5.0 \mu \mathrm{M}$ Fe-EDDHA was higher than in control flasks where no iron was added. Above $10.0 \mu \mathrm{M}$, INA declined substantially. Thus, at 5.0 $\mu \mathrm{M}$ Fe-EDDHA the INA was still high, whereas pseudobactin production had already decreased (data not shown).

To investigate if the conditions in the radish rhizosphere would favor the production of pseudobactin, the INA of WCS358pvdinaZ was determined in the rhizosphere of plants grown in soil (Fig. 3). The INA was monitored during the first 4 days, as well as at 10 days after planting. In the first $24 \mathrm{~h}$ period, the INA level increased 20-fold, after which it decreased again to the same level and remained at that level at 11 days. All values after 1 and 10 days correspond to an in vitro Fe-EDDHA concentration between 5.0 and $10.0 \mu \mathrm{M}$. At these concentrations, WCS358 produces little or no pseudobactin. In the first 3 days, the population density of the reporter strain (Fig. 3), as well as that of wild-type strain WCS358 (data not shown), increased approximately 40-fold, after which they decreased again.

Disease suppression by RE8. The disease-suppressive mechanism of RE8 was also investigated. The pseudobactin-negative mutant of RE8 (RE8-30) was tested for its ability to suppress Fusarium wilt. In eight independent bioassays, treatment with RE8-30 always resulted in the same percentage of diseased plants compared to the parental strain RE8. In six of these eight bioassays, both strains suppressed disease (data not shown). Strain RE8 was also tested for induction of systemic resistance in the bioassay described by Leeman et al. (29). In this bioassay, the pathogen and the biocontrol bacterium remained at spatially separated sites on the roots. As negative and positive controls, $P$.

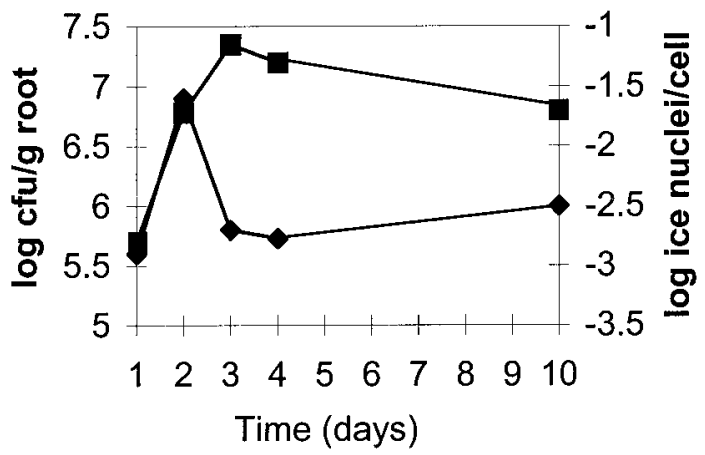

Fig. 3. Ice nucleating activity $\left({ }^{10} \log\right.$ ice nuclei/cell) $(\bullet)$ and rhizosphere populations $\left({ }^{10} \mathrm{log}\right.$ CFU/g root) (ם) of WCS358 containing pvd-inaZ. Fiveday-old radish seedlings were planted in soil mixed with WCS358pvd-inaZ $\left(10^{6} \mathrm{CFU} / \mathrm{g}\right.$ of soil). The numbers of culturable cells and ice nuclei were quantified at $0,1,2,3$, and 10 days after planting. 
putida WCS358 and $P$. fluorescens WCS417, respectively, were included (29). In this bioassay, both RE8 and WCS417 suppressed disease, whereas WCS358 was ineffective (data not shown).

Disease suppression by the combination of WCS358 and RE8. Disease suppression by the combination of strains WCS358 and RE8 was investigated in the potting soil bioassay. When both single strains suppressed disease in this bioassay, the combination resulted in significantly enhanced disease suppression as compared to the single strains (Fig. 4A). However, when only WCS358 suppressed disease and strain RE8 failed, the combination of RE8 and WCS358 resulted in a disease suppression comparable to that caused by WCS358 alone (Fig. 4B). Conversely, when strain WCS358 was ineffective in lowering the percentage of diseased plants compared to the control (Fig. 4C), but RE8 did reduce disease significantly, the combination resulted in disease suppression comparable to that by the effective RE8.

To check whether the pseudobactin produced by WCS358 is important in the enhanced disease suppression by the combination of WCS358 with RE8, disease suppression by RE8, WCS358, JM218, the combination of WCS358 and RE8, and the combination of JM218 and RE8 were tested. In two bioassays, all single applications including JM218 resulted in a significantly lower percentage of diseased plants. Figure 5 shows a representative experiment. Both combinations resulted in enhanced disease suppression, be it at the border of significance for the combination of WCS358 with RE8.

\section{DISCUSSION}

In several bioassays, strain WCS358 was able to suppress Fusarium wilt of radish by effectively competing for iron. The pseudobactin-negative mutant JM218 did not suppress disease, and addition of Fe-EDDHA to the nutrient solution for the plants diminished the disease-suppressive effect of WCS358 (Fig. 1). The involvement of pseudobactin in Fusarium wilt control was demonstrated previously $(26,46)$. Surprisingly, in some bioassays pseudobactin-negative mutants of WCS358 suppressed disease to the same extent as the parental strain (Figs. 2 and 5). It is not clear by which disease-suppressive mechanisms these pseudobactinnegative mutants are able to suppress disease. Unlike for example, $P$. fluorescens strain WCS374 that produces the siderophore pseudomonine in addition to the fluorescent pseudobactin type siderophore (40), WCS358 only produces pseudobactin (39). Induction of systemic resistance can be excluded because WCS358 did not induce systemic resistance nor can its pseudobactin-negative mutant (27). Antibiotic compounds active against Fusarium spp. have been identified in in vitro antagonism assays $(2,5)$, but for WCS358 none has been found (45). In vitro antagonism against $F$. oxysporum f. sp. raphani could be fully explained by pseudobactin-mediated competition for iron (45). However, it

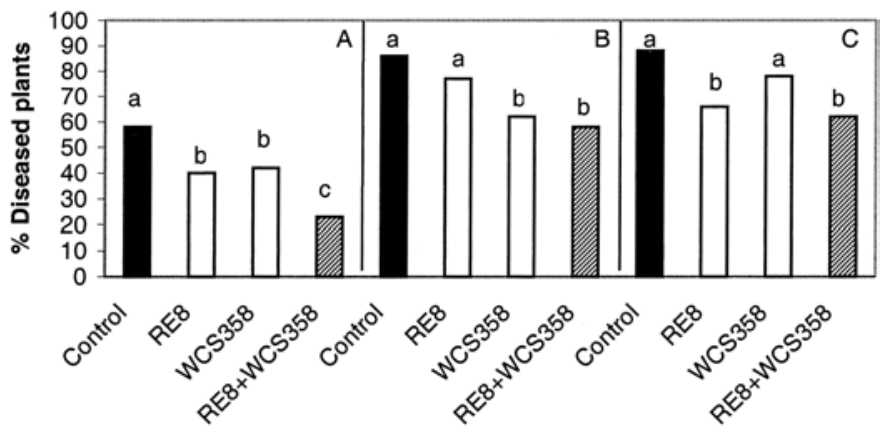

Fig. 4. Suppression of Fusarium wilt of radish by $P$. putida strains RE8, WCS358, and their combination in three independent bioassays showing varying results. Details as described in the legend to Figure 1. Control treatment is Fusarium alone. cannot be excluded that WCS358 and/or its pseudobactin-negative mutants produce antibiotic compounds in the rhizosphere. Chitinolytic enzymes, such as were recently demonstrated to be involved in suppression of Fusarium wilt of cucumber (53), are not produced by WCS358 on chitin containing KB medium (J. Folders, personal communication). Competition for substrate can be involved in interactions between pseudomonads and pathogenic Fusarium strains (11), as was demonstrated also for antagonism between a nonpathogenic and a pathogenic Fusarium strain $(6,32)$.

Disease suppression by $P$. putida strain RE8 does not depend on the pseudobactin produced by this strain because the pseudobactin-negative mutant of this strain (RE8-30) suppressed disease to a comparable level as the parental strain. Instead, strain RE8 is able to induce systemic resistance.

When the combination of WCS358 and RE8 was mixed through soil, it resulted in enhanced disease suppression compared to treatments with the single strains (Fig. 4A). This enhanced disease suppression could be the result of pseudobactin-mediated competition for iron combined with induced systemic resistance. However, when JM218 was combined with RE8, those experiments also resulted in enhanced disease suppression, indicating that the pseudobactin of WCS358 does not necessarily play a role in the enhanced disease control by the combination (Fig. 5).

Improved disease control by the combination of WCS358 and RE8 occurred only when each strain by itself was effective in reducing disease. The reason why sometimes treatments with either strain did not result in disease suppression remains unclear. It is unlikely to be due to insufficient root colonization. The population density of WCS358 in the bioassay where it did not suppress disease (Fig. 4C) was $6.3 \times 10^{5} \mathrm{CFU} / \mathrm{g}$ root at 10 and 21 days after sowing. These population densities are comparable to population densities demonstrated to result in disease suppression (46). Although population densities of RE8 were not measured in the experiment depicted in Figure 4B, results from other bioassays confirmed that in spite of high densities of RE8 reached in the rhizosphere, disease suppression does not always occur. Despite the fact that the combination of strains WCS358 and RE8 resulted in improved and more consistent biocontrol, strain RE8 negatively influenced root colonization by WCS358. When both strains were coinoculated in soil, rhizosphere populations of WCS358 were significantly lower compared to when WCS358 was inoculated alone. While the population of RE8 in the rhizosphere in the combined application was significantly higher after 13 days, after 25 days it was comparable to the single treatment (Table 2). The pseudobactin siderophore of strain WCS358 inhibits in vitro growth of RE8, whereas RE8 does not affect growth of WCS358. Apparently, in these experiments competition for iron in the rhizosphere between WCS358 and RE8 was of no significance for the population densities of both strains. In contrast, in similar experiments when WCS358 was coinoculated with $P$. fluorescens strain WCS374, the latter strain maintained its population density

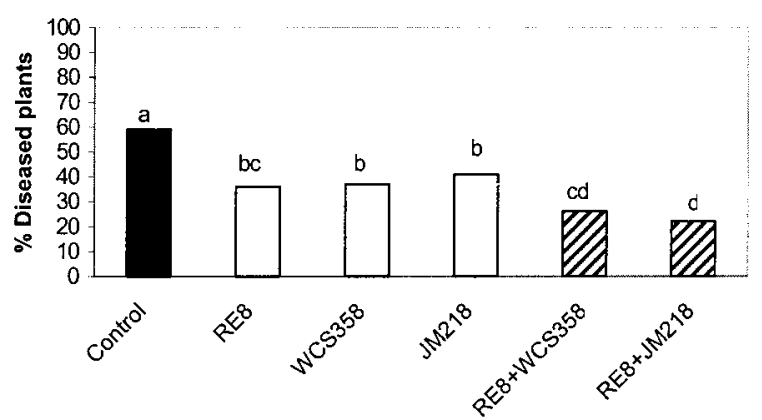

Fig. 5. Suppression of Fusarium wilt of radish by $P$. putida strains RE8, WCS358, JM218, and their combinations. Details as described in the legend to Figure 1. Control treatment is Fusarium alone. 
in the rhizosphere only when transformed with the pseudobactin receptor PupA for uptake of ferric pseudobactin 358 (47).

The INA values determined in the rhizosphere (Fig. 3) indicate that the iron availability in the soil used was at the border of iron sufficiency. Therefore, it is likely that at most, only limited competition for iron occurred between strains WCS358 and RE8. It is also possible that WCS358 and RE8 colonize different niches. This stresses again that in vitro observations cannot be generalized and extrapolated to in vivo conditions, as evidenced also by De Boer et al. (7). The population densities of WCS358 that developed in the presence of RE8 were still above the threshold level required for disease suppression (46). This can explain the enhanced effect on disease suppression by the combination.

The improved biocontrol by the combination of WCS358 and RE8 appears to result from combining different disease-suppressive mechanisms. In all bioassays performed, at least one strain suppressed disease, and the combination always resulted in disease suppression. Enhanced suppression of take-all of wheat by a consortium of a nonpathogenic isolate of Gaeumannomyces graminis var. graminis and a mixture of pseudomonads was reported to be the result of combining different disease-suppressive properties. Here, direct competition for substrates and favored sites in and on the roots by $G$. graminis was combined with antibiotic production by the pseudomonads (8). Dunne et al. (10) similarly demonstrated that combining proteolytic and phloroglucinol-producing bacteria can improve biocontrol of Pythiummediated damping-off of sugar beet. The improved control of Fusarium wilt of carnation by the combination of the nonpathogenic $F$. oxysporum strain Fo47 with $P$. putida WCS358 was the indirect effect of competition for iron that made the pathogenic $F$. oxysporum more sensitive to competition for substrate with the nonpathogenic strain $(31,32)$. Suppression of Botrytis cinerea on strawberry was improved by combining the biocontrol agents Pichia guilermondii and Bacillus mycoides (15). In this case, the yeast effectively competed with $B$. cinerea for nutrients, whereas the bacterium secreted inhibitory compounds and activated the defense systems of the host (16).

Combining biocontrol agents is not only advantageous because it can lead to enhanced levels of disease suppression, it is also advantageous when an application of one of the single strains failed to suppress disease, because the combination still resulted in disease control (Fig. 4B and C). The reason why application of single strains does not always control disease might be related to insufficient root colonization. However, in the present bioassays strains colonized the roots to a similar level in bioassays that did, and in bioassays that did not result in disease suppression. It can be concluded that $P$. putida strains WCS358 and RE8 have different disease-suppressive mechanisms: pseudobactin-mediated competition for iron and/or another yet unknown disease suppressive trait for WCS358, and induction of systemic resistance for RE8. Combining these mechanisms by applying a mixture of the biocontrol strains leads to more effective, or at least more reliable, biocontrol of Fusarium wilt of radish.

\section{ACKNOWLEDGMENTS}

We thank J. Loper for providing us with strain WCS358 pvd-inaZ. This work was supported by the Netherlands Technology Foundation (STW).

\section{LITERATURE CITED}

1. Alabouvette, C., Schippers, B., Lemanceau, P., and Bakker, P. A. H. M. 1998. Biological control of fusarium wilts. Pages 15-36 in: PlantMicrobe Interactions and Biological Control. G. J. Boland and L. D. Kuykendall, eds. Marcel Dekker, New York.

2. Anjaiah, V., Koedam, N., Nowak-Thompson, B., Loper, J. E., Höfte, M., Tambong, J. T., and Cornelis, P. 1998. Involvement of phenazines and anthranilate in the antagonism of Pseudomonas aeruginosa PNA1 and Tn5 derivatives toward Fusarium spp. and Pythium spp. Mol. Plant-
Microbe Interact. 11:847-854.

3. Bakker, P. A. H. M., Weisbeek, P. J., and Schippers, B. 1988. Siderophore production by plant growth-promoting Pseudomonas spp. J. Plant Nutr. 11:925-933.

4. Camprubí, A., Calvet, C., and Estaún, V. 1995. Growth enhancement of Citrus reshni after inoculation with Glomus intraradices and Trichoderma aureoviride and associated effects on microbial populations and enzyme activity in potting mixes. Plant Soil 173:233-238.

5. Chin-A-Woeng, T. F. C., Bloemberg, G. V., Van der Bij, A. J., Van der Drift, K. M. G. F., Schripsema, J., Kroon, B., Scheffer, R. J., Keel, C., Bakker, P. A. H. M., Tichy, H. V., De Bruijn, F. J., Thomas-Oates, J. E., and Lugtenberg, B. J. J. 1998. Biocontrol by phenazine-1-carboxamideproducing Pseudomonas chlororaphis PCL1391 of tomato root rot caused by Fusarium oxysporum f. sp. radicis-lycopersici. Mol. PlantMicrobe Interact. 11:1069-1077.

6. Couteaudier, Y., and Alabouvette, C. 1990. Quantitative comparison of Fusarium oxysporum competitiveness in relation to carbon utilization. FEMS (Fed. Eur. Microbiol. Soc.) Microbiol. Ecol. 74:261-268.

7. De Boer, M., Van der Sluis, I., Van Loon, L. C., and Bakker, P. A. H. M. 1999. Combining fluorescent Pseudomonas spp. strains to enhance suppression of fusarium wilt of radish. Eur. J. Plant Pathol.105:201-210.

8. Duffy, B. K., and Weller, D. M. 1995. Use of Gaeumannomyces graminis var. graminis alone and in combination with fluorescent Pseudomonas spp. to suppress take-all of wheat. Plant Dis. 79:907-911.

9. Duijff, B. J., Recorbet, G., Bakker, P. A. H. M., Loper, J. E., and Lemanceau, P. 1999. Microbial antagonism at the root level is involved in the suppression of fusarium wilt by the combination of nonpathogenic Fusarium oxysporum Fo47 and Pseudomonas putida WCS358. Phytopathology 89:1073-1079.

10. Dunne, C., Moenne-Loccoz, Y., McCarthy, J., Higgins, P., Powell, J., Dowling, D. N., and O'Gara, F. 1998. Combining proteolytic and phloroglucinol-producing bacteria for improved biocontrol of Pythiummediated damping-off of sugar beet. Plant Pathol. 47:299-307.

11. Elad, Y., and Baker, R. 1985. The role of competition for iron and carbon in suppression of chlamydospore germination of Fusarium spp. by Pseudomonas spp. Phytopathology 75:1053-1059.

12. Fuchs, J. G., Moenne-Loccoz, Y., and Défago, G. 1997. Nonpathogenic Fusarium oxysporum strain Fo47 induces resistance to fusarium wilt in tomato. Plant Dis. 81:492-496.

13. Geels, F. P., and Schippers, B. 1983. Selection of antagonistic fluorescent Pseudomonas spp. and their root colonization and persistence following treatment of seed potatoes. Phytopathol. Z. 180:193-206.

14. Glandorf, D. C. M., Brand I., Bakker, P. A. H. M., and Schippers, B. 1992. Stability of rifampicin resistance as a marker for root colonization studies of Pseudomonas putida in the field. Plant Soil 147:135-142.

15. Guetsky, R., Shtienberg, D., Elad, Y., and Dinoor, A. 2001. Combining biocontrol agents to reduce the variability of biological control. Phytopathology 91:621-627.

16. Guetsky, R., Shtienberg, D., Elad, Y., Fischer, E., and Dinoor, A. 2002. Improving biological control by combining biocontrol agents each with several mechanisms of disease suppression. Phytopathology 92:976-985.

17. Handelsman, J., and Stabb, E. V. 1996. Biocontrol of soilborne plant pathogens. Plant Cell 8:1855-1869.

18. Hoagland, D. R., and Arnon, D. I. 1938. The water culture method for growing plants without soil. Bull. Calif. Agric. Exp. Stn. 347:36-39.

19. Höfflich, G., Wiehe, W., and Kühn, G. 1994. Plant growth stimulation by inoculation with symbiotic and associative rhizosphere microorganisms. Experientia 50:897-905.

20. Janisiewicz, W. J., and Bors, B. 1995. Development of a microbial community of bacterial and yeast antagonists to control wound-invading postharvest pathogens of fruits. Appl. Environ. Microbiol. 61:32613267.

21. Jetiyanon, K., and Kloepper, J. W. 2002. Mixtures of plant growthpromoting rhizobacteria for induction of resistance against multiple plant diseases. Biol. Control 24:285-291.

22. Jorgensen, R. A., Rothstein, S. J., and Reznikoff, W. S. 1979. A restriction enzyme cleavage map of $\operatorname{Tn} 5$ and location of a region encoding neomycin resistance. Mol. Gen. Genet. 177:65-72.

23. King, E. O., Ward, M. K., and Raney, D. E. 1954. Two simple media for the demonstration of pyocyanin and fluorescin. J. Lab. Clin. Med. 44:301-307.

24. Kragelund, L., and Nybroe, O. 1996. Competition between Pseudomonas fluorescens Ag1 and Alcaligenes eutrophus JMP134 (pJP4) during colonization of barley roots. FEMS Microbiol. Ecol. 20:41-51.

25. Lamers, J. B., Schippers, B., and Geels, F. P. 1988. Soilborne disease of wheat in the Netherlands and results of seed bacterization with pseudomonads against Gaeumannomyces graminis var. tritici. Pages 134-139 in: Cereal Breeding Related to Integrated Production. M. L. Jorna and L. A. Slootmaker, eds. Pudoc, Wageningen, the Netherlands. 
26. Leeman, M., Den Ouden, F. M., van Pelt, J. A., Cornelissen, C., Matamala-Garros, A., Bakker, P. A. H. M., and Schippers, B. 1996. Suppression of fusarium wilt of radish by co-inoculation of fluorescent Pseudomonas spp. and root-colonizing fungi. Eur. J. Plant Pathol. 102:21-31.

27. Leeman, M., Den Ouden, F. M., van Pelt, J. A., Dirkx, F. P. M., Steijl, H., Bakker, P. A. H. M., and Schippers, B. 1996. Iron availability affects induction of systemic resistance to fusarium wilt of radish by Pseudomonas fluorescens. Phytopathology 86:149-155.

28. Leeman, M., Raaijmakers, J. M., Bakker, P. A. H. M, and Schippers, B. 1991. Immunofluorescence colony-staining for monitoring pseudomonads introduced into soil. Pages 374-380 in: Biotic Interactions and Soilborne Diseases. A. B. R. Beemster, G. J. Bollen, M. Gerlagh, M. A. Ruisen, B. Schippers, and A. Tempel, eds. Elsevier, Amsterdam.

29. Leeman, M., Van Pelt, J. A., Den Ouden, F. M., Heinsbroek, M., Bakker, P. A. H. M., and Schippers, B. 1995. Induction of systemic resistance by Pseudomonas fluorescens in radish cultivars differing in susceptibility to fusarium wilt, using a novel bioassay. Eur. J. Plant Pathol. 101:655-664.

30. Leeman, M., Van Pelt, J. A., Hendrickx, M. J., Scheffer, R. J., Bakker, P. A. H. M., and Schippers, B. 1995. Biocontrol of fusarium wilt of radish in commercial greenhouse trials by seed treatment with Pseudomonas fluorescens WCS374. Phytopathology 85:1301-1305.

31. Lemanceau, P., Bakker, P. A. H. M., De Kogel, W. J., Alabouvette, C., and Schippers, B. 1992. Effect of pseudobactin 358 production by Pseudomonas putida WCS358 on suppression of fusarium wilt of carnations by nonpathogenic Fusarium oxysporum Fo47. Appl. Environ. Microbiol. 58:2978-2982.

32. Lemanceau, P., Bakker, P. A. H. M., De Kogel, W. J., Alabouvette, C., and Schippers, B. 1993. Antagonistic effect of nonpathogenic Fusarium oxysporum Fo47 and pseudobactin 358 upon pathogenic Fusarium oxysporum f. sp. dianthi. Appl. Environ. Microbiol. 59:74-82.

33. Lindow, S. E. 1990. Bacterial ice-nucleation activity. Pages 185-198 in: Methods in Phytobacteriology. Z. Klement, K. Rudolf, and D. C. Sands, eds. Akadémiai Kiadó, Budapest, Hungary.

34. Loper, J. E., and Henkels, M. D. 1997. Availability of iron to Pseudomonas fluorescens in rhizosphere and bulk soil evaluated with an ice nucleation reporter gene. Appl. Environ. Microbiol. 63:99-105.

35. Loper, J. E., and Henkels, M. D. 1999. Utilization of heterologous siderophores enhances levels of iron available of Pseudomonas putida in the rhizosphere. Appl. Environ. Microbiol. 65:5357-5363.

36. Loper, J. E., and Lindow, S. E. 1994. A biological sensor for iron available to bacteria in their habitats on plant surfaces. Appl. Environ. Microbiol. 60:1934-1941.

37. Loper, J. E., Suslow, T. V., and Schroth, M. N. 1984. Lognormal distribution of bacterial populations in the rhizosphere. Phytopathology 74:1454-1460.

38. Mao, W., Lewis, J. A., Lumsden, R. D., and Hebbar, K. P. 1998. Biocontrol of selected soilborne diseases of tomato and pepper plants. Crop Prot. 17:535-542.

39. Marugg, J. D., Van Spanje, M., Hoekstra, W. P. M., Schippers, B., and Weisbeek, P. J. 1985. Isolation and analysis of genes involved in siderophore biosynthesis in plant growth-stimulating Pseudomonas putida WCS358. J. Bacteriol. 164:563-570.

40. Mercado-Banco, J., Van der Drift, K. M. G. M., Olsson, P. E., ThomasOates, J. E., Van Loon, L. C., and Bakker, P. A. H. M. 2001. Analysis of the pms $C E A B$ gene cluster involved in biosynthesis of salicylic acid and the siderophore pseudomonine in the biocontrol strain Pseudomonas fluorescens WCS374. J. Bacteriol. 183:1909-1920.

41. Meyer, J. M., and Abdallah, M. A. 1978. The fluorescent pigment of Pseudomonas fluorescens: Biosynthesis, purification and physico- chemical properties. J. Gen. Microbiol. 107:319-328.

42. Miller, J. H. 1972. Experiments in Molecular Genetics. Cold Spring Harbor Laboratory, Cold Spring Harbor, NY.

43. Pierson, E. A., and Weller, D. M. 1994. Use of mixtures of fluorescent pseudomonads to suppress take-all and improve the growth of wheat. Phytopathology 84:940-947.

44. Pieterse, C. M. J., Van Wees, S. C. M., Van Pelt, J. A., Knoester, M., Laan, R., Gerrits, H., Weisbeek, P. J., and Van Loon, L. C. 1998. A novel signaling pathway controlling induced systemic resistance in Arabidopsis. Plant Cell 10:1571-1580.

45. Raaijmakers, J. M. 1994. Microbial interactions in the rhizosphere: Root colonization by Pseudomonas spp. and suppression of fusarium wilt. Ph.D. diss. Utrecht University, Utrecht, the Netherlands.

46. Raaijmakers, J. M., Leeman, M., Van Oorschot, M. M. P., Van der Sluis, I., Schippers, B., and Bakker, P. A. H. M. 1995. Dose-response relationships in biological control of fusarium wilt of radish by Pseudomonas spp. Phytopathology 85:1075-1081.

47. Raaijmakers, J. M., van der Sluis, I., Koster, M., Bakker, P. A. H. M., Weisbeek, P. J., and Schippers, B. 1995. Utilization of heterologous siderophores and rhizosphere competence of fluorescent Pseudomonas spp. Can. J. Microbiol 41:126-135.

48. Raupach, G. S., and Kloepper, J. W. 1998. Mixtures of plant growthpromoting rhizobacteria enhance biological control of multiple cucumber pathogens. Phytopathology 88:1158-1164.

49. Schippers, B. 1992. Prospects for management of natural suppressiveness to control soilborne pathogens. Pages 21-34 in: Biological Control of Plant Diseases, Progress and Challenges For the Future. E. C. Tjamos, G. C. Papavizas, and R. J. Cook, eds. Plenum Press, New York.

50. Schippers, B., Bakker, A. W., and Bakker, P. A. H. M. 1987. Interactions of deleterious and beneficial rhizosphere microorganisms and the effect of cropping practices. Annu. Rev. Phytopathol. 25:339-358.

51. Schisler, D. A., Slininger, P. J., and Bothast, R. J. 1997. Effects of antagonist cell concentration and two-strain mixtures on biological control of fusarium dry rot of potatoes. Phytopathology 87:177-183.

52. Schwyn, B., and Neilands, J. B. 1987. Universal chemical assay for the detection and determination of siderophores. Anal. Biochem.160:47-56.

53. Singh, P. P., Shin, Y. C., Park, C. S., and Chung, Y. R. 1999. Biological control of fusarium wilt of cucumber by chitinolytic bacteria. Phytopathology 89:92-99.

54. Sung, K. C., and Chung, Y. R. 1997. Enhanced suppression of rice sheath blight using combination of bacteria which produce chitinases or antibiotics. Pages 370-372 in: Plant Growth-Promoting Rhizobacteria: Present Status and Future Prospects. A. Ogoshi, K. Kobayashi, Y. Homma, F. Kodama, N. Kondo, and S. Akino, eds. Faculty of Agriculture, Hokkaido University, Sapporo, Japan.

55. Van Loon, L. C., Bakker, P. A H. M., and Pieterse, C. M. J. 1998. Systemic resistance induced by rhizosphere bacteria. Annu. Rev. Phytopathol. 36:453-483.

56. Van Peer, R., Niemann, G. J., and Schippers, B. 1991. Induced resistance and phytoalexin accumulation in biological control of fusarium wilt of carnation by Pseudomonas sp. WCS417r. Phytopathology 81:728-734.

57. Van Vuurde, J. W. L. 1990. Immunofluorescence colony staining. Pages 299-305 in: Serological Methods for Detection and Identification of Viral and Bacterial Plant Pathogens. R. Hampton, E. Ball, and S. De Boer, eds. The American Phytopathological Society, St. Paul, MN.

58. Van Wees, S. C. M., Pieterse, C. M. J., Trijssenaar, A., Van 't Westende, Y. A. M., Hartog, F., and Van Loon, L. C. 1997. Differential induction of systemic resistance in Arabidopsis by biocontrol bacteria. Mol. PlantMicrobe Interact. 10:716-724.

59. Weller, D. M. 1988. Biological control of soilborne plant pathogens in the rhizosphere with bacteria. Annu. Rev. Phytopathol. 26:379-407. 